\title{
MEMAHAMI KONSEP NIAT DALAM BERIBADAH HINGGA ISTITHA'AH HAJI DALAM STUDI FIQH
}

\author{
Rinwanto \\ STIT Makhdum Ibrahim Tuban \\ rinwanto@stitmatuban.ac.id \\ Shofiyullahul Kahfi \\ STIT Makhdum Ibrahim Tuban \\ shofiyullahulkahfi@stitmatuban.ac.id
}

\begin{abstract}
Abstrak
Fiqih menawarkan sebuah jawaban yang beragam terhadap berbagai fenomena kehidupan masyarakat baik dalam peribadatan maupun dalam muamalah. Menurut Syekh Zainudin Al-Malibari di dalam kitab Mandhûmatu Hidâyatil Adzkiyâ' ilâ Tharîqil Auliyâ', bahwa ada 3 (tiga) ilmu yang wajib dipelajari oleh setiap orang Muslim dengan kewajiban fardlu 'ain. Ketiga ilmu itu adalah ilmu yang menjadikan ibadah menjadi sah, yang mengesahkan aqidah, dan yang menjadikan hati bersih.

Ilmu yang menjadikan sahnya ibadah kepada Allah adalah ilmu fiqih yang membahas tentang bagaimana semestinya seorang Muslim beribadah kepada Allah. Sebagai contoh, mempelajari ilmu tentang bagaimana caranya shalat yang benar dan baik. keabsahan shalat, seperti caranya niat dalam beribadah, tata cara dan sarana yang digunakan untuk bersuci, cara mensucikan berbagai macam najis, bertayamum, beristinja dan lain sebagainya. Seorang Muslim juga wajib mempelajari ilmu-ilmu yang berkaitan dengan ibadah-ibadah lain seperti puasa, zakat, haji dan sebagainya.

Ilmu-ilmu ini fardlu ain hukumnya untuk dipelajari mengingat amalan seseorang yang tidak didasari dengan ilmu maka amalan yang dilakukan menjadi batal, tak diterima. Sebagaimana dituturkan Ibnu Ruslan dalam kitab Zubad:

وكل من بغير علم يعمل أعماله مردودة لا تقبل

Setiap orang yang beramal tanpa ilmu Maka amalnya tertolak, tak diterima

Tulisan ini disusun dengan menggunakan metode kepustakaan.Yaitu dengan membaca, memahami, dan menyimpulkan data-data yang dikumpulkan dari sumber-sumber
\end{abstract}

Kata kunci: Niat, Isthitha'ah, Studi fiqh.

\section{PENDAHULUAN}

Manusia ialah hayawannathiq. Keistimewaan manusia ialah, ia dapat berpikir. Secara anatomis, hewan pun memiliki otak. Sehingga bisa dikatakan hewan pun berpikir.Namun hewan tidaklah nathiq, tidak berbicara.Sedangkan manusia dapat berbicara. Kemampuan manusia berbahasa inilah yang menjadi bukti kongkret bahwa manusia dapat berpikir analitis. Manusia mampu menyadari adanya dirinya sekaligus menyadari apa yang ia lakukan. Sehingga, manusia mampu memperbaiki kualitas hidupnya. 
Dan sehebat apapun manusia, manusia tidak akan mampu hidup sendiri. Karena manusia adalah makhluk sosial. Manusia hidup bersama, bahu membahu.Tapi, karena perbedaan, manusia akan sampai pada konflik. Jika tak ada aturan hukum, kehidupan manusia akan kacau (chaos).

Hukum sebagai aturan ini pun takakan luput dari daya manusia yang suka bertanya untuk mencari jawaban. Maka dari itu fiqih muncul sebagai rujukan dalam tatanan kehidupan manusia sehari-hari yang bersinggungan dengan hukum. Yang berdasarkan Al-quran, Assunah dan ijma ulama yang menjadi prodak Hukum Islam, karena beragamnya ijtihat para ulama perlu kiranya adanya pengkajian tentang fiqih perbandingan guna mempeluas wawasan dan hazanah keilmuan.

\section{ISI DAN PEMBAHASAN}

\section{A. Niat dalam Beribadah}

Niat ialah bermaksud melakukan sesuatu (Wahbah, 1985:225). Niat dalam beribadah difungsikan untuk membedakan antara satu ibadah dengan yang lain agar tidak terjadi kerancuan. Sebab, terkadang terdapat suatu tindakan dimana hanya dapat dibedakan dengan niatnya.

Dalam hukum Islam, niat mengambil porsi yang begitu besar. Dasar pijakan hukumnya ialah firman Allah Swt. Sekaligus sabda Rasululloh Saw, yaitu:

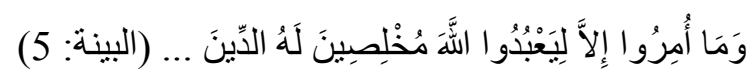

"Padahal mereka hanya diperintah menyembah Allah dengan ikhlas mentaatiNya semata-mata karena (menjalankan) agama" (Q.S. Al-Bayyinah:5) (Al-Qur'an dan Terjemahnya, 2005:303)

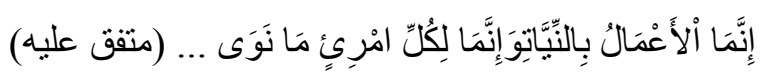

"Setiap tindakan tergantung dari niatnya dan setiap orang mendapat hasil sesuai tujuannya"

Berdasarkan ayat dan hadits tersebut di atas, para fuqoha' memiliki kesimpulan yang berbeda-beda. Perbedaan tersebut dibandang dari banyak sisi dan berbeda-beda tiap babnya. Seperti niat wudhu', disebutkan oleh Ibnu Rusyid bahwa sebab perbedaan pendapat tersebut ialah ambiguitas niat sebagai ma'qulah al-ma'na atau ghair ma'qulah al-ma'na (Muhammad, 1995:30).

\section{B. Tata Cara dan Sarana yang Digunakan untuk Bersuci}

Bersuci atau thaharah didefinisikan sebagai bersih dari najis, baik berbentuk konkret yang berupa kotoran maupun abstrak yang berupa hadats (Wahbah, 1985:201). 
Hukum thaharah sendiri adalah wajib, diantara yang wajib tersebut ialah wudhu, mandi jinabat, tayammum dan menghilangkan najis (Wahbah, 1985:204). Berikut ini rincian sarana bersuci menurut empat madzhab (Wahbah, 1985:204-224):

\begin{tabular}{|c|c|c|c|}
\hline الحنابلة & الشافعية & المالكية & الحنفية \\
\hline 2. & 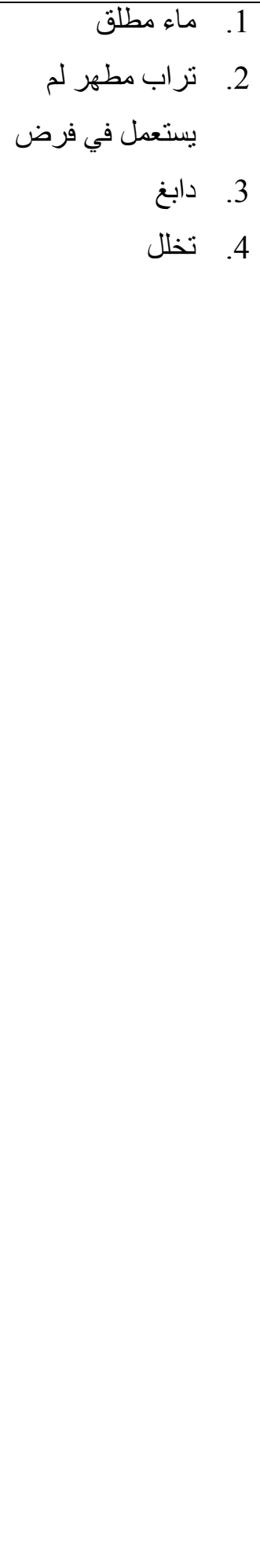 & 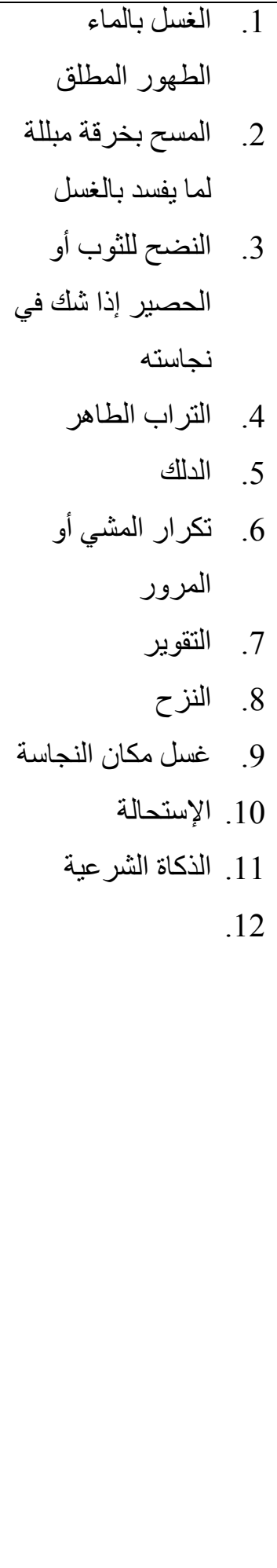 & 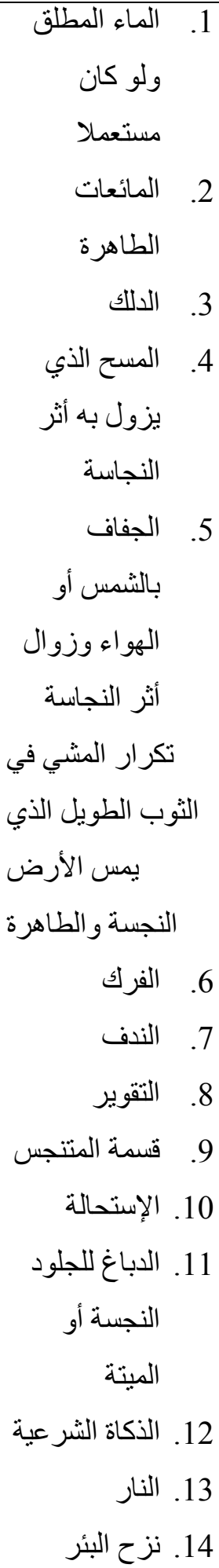 \\
\hline
\end{tabular}




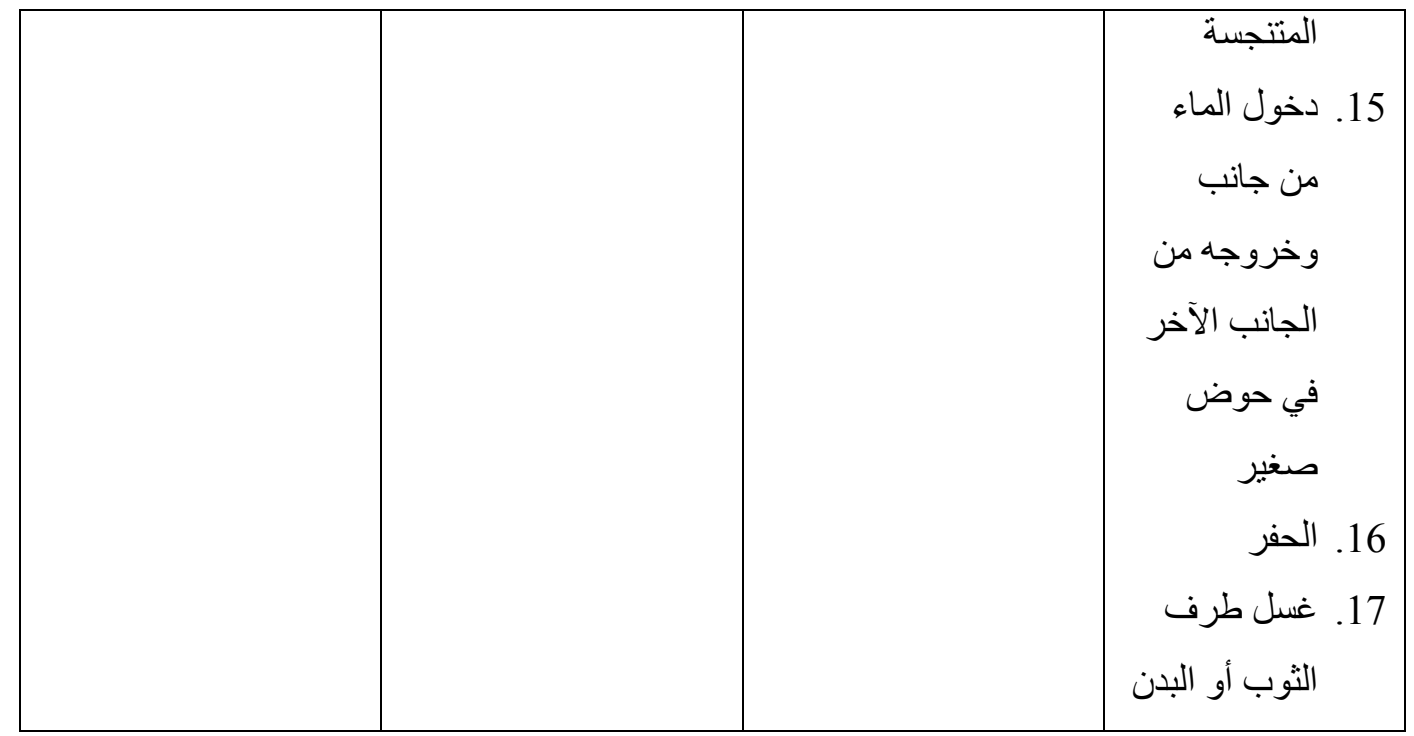

\section{Hukum Bacaan Basmalah dalam Sholat}

Terkait bacaan basmalah dalam sholat, 'ulama empat madzhab berbeda pandangan. Hanafiyyah dan Hanabilah mengatakan bahwa membaca basmalah dalam sholat berhukum sunnah, Syafi'iyyah mengatakan berhukum wajib, sedangkan Malikiyyah mengatakan berhukum makruh. (Rahman, 2011:232)

\section{Do'a iftitah dan Qunut}

Membaca do'a iftitah menurut Hanafiyyah, Syafi'iyyah dan Hanabilah berhukum sunnah. Sedangkan menurut pendapat masyhur Malikiyyah berhukum makruh. (Rahman, 2011:231)

\section{E. Hukum Sholat Berjama'ah}

Menurut empat madzhab Hanafiyyah, Malikiyyah, Syafi'iyyah dan Hanabilah, sholat jama'ah berhukum sunnah atau fardhu kifayah. Sedangkan menurut madzhab dzhahiriyyah, sholat berjama'ah berhukum fardhu 'ain. (Muhammad, 1995:331)

\section{F. Sholat Jum'at dan Ta'addudul Jum'at.}

Hukum salat jum'at, Shalat jum'at berhukum fardu bagi setiap orang yang telah memenuhi syarat-syarat, salat jumat bukanlah ebagai pengantu dari salat duhur maka apabila seseorang ketingalan salat jum'at ia diwajibkan salat dhuhur empat rokaat kwajiban salat jum'at itu telah ditetapkan dal;am kitab sunah maupun ijma. (Rahman, 2011:341)

Syarat-syarat salat jum'at itu sebagaimana shalat biasa namun terdapat beberapa tambahan. 
Hanafiyyah

1. Syarat wajib

a. Laki-laki Merdeka.

b. Sehat.

c. Bermukim tidak jauh dari tempat dilaksanakanya salat jum'at (kurang dari 6 mil/ 1000 dhiro/ $5.040 \mathrm{~m}$ ).

d. Berakal.

e. Baligh.

2. Syarat Sah

a. dilaksanakn diperkotaan, batasan perkotaan menurut madhab abihanifah adalah setiap tempat yang terdapat 1 amir (pemimpin) dan qodhi yang mampu menegakkan peraturan.

b. Idin sulton atau wakilnya.

c. Masuk waktu.

d. Ada khutbah.

e. Khotbah dilakukan sebelum sholat.

f. Jama'ah minimal 3 orang selain imam.

g. Imamnya adalahyang diidini masyarakat.

Malikiyyah

1. Syarat wajib

a. Laki-laki.

b. Merdeka.

c. Tidak ada udhur yang membolehkan meningalkan shalat.

d. Bisa melihat.

e. Bukan orang yang tua renta.

f. Tidak waktu musim dingin dan musim panas.

g. Aman dari orang dholim yang akan memukul secara dholim.

h. Aman baik harta, harga diri dan jiwa.

i. Mukim di dairah yang dekat di dirikan salat jum'at kurang dari 3,1/3 mil.

j. Tingal di dairah itu secara menetap.

2. Syarat Sah

a. Menetapnya penduduk di suatu dairah atau arah (juga menjadi syatar wajib). 
b.Hadirnya 12 orang selain imam.

c. Adanya imam yang memenuhi 2 syarat: 1 mukim atau musafir yang niat mukim selama 4 hari 2. Menjadi khotib.

d.Dua khotbah.

e.Di tempat yang bias mengumpulkan orang banyak.

Syafi'iyyah

1. Syarat wajib

a. Syarat-syarat yang telah tercantum didalam syarat wajibnya salat (1-10 malikiyah).

2. Syarat sah

a. Sholat dan dua khutbahnya dilaksanakan pada waktu dhuhur, dengan yakin.

b. Dilaksanakan disebuah bangunan yang memuat banyak orang.

c. Dilaksanakan dengan berjama'ah, dengan syarat-syaratnya yang terdahulu.

d. Jama'ah berjumlah 40 orang dengan syarat-syaratnya.

e. Pelaksanaan sholat jum'atl ebih dahulu, dari pada masjid yang lain didaerahnya.

f. Mendahulkan dua khutbah dengan rukun-rukun dan syaratnya.

Hanabilah

1. Syarat wajib

a. Diantaranya Syarat-syarat yang telah disebutkan malikiyyah, hanafiyyah, dan syafi'iyyah.

2. Syarat sah

a.Masuk waktu.

b. Dilaksanakan di kota atau di desa, dengan cara yang di sebutkan dalam syarat wajib,kecuali menurat hanafiyyah.

c. berjumlah 40 atau lebih beserta imam.

d. dua khutbah, dengan syarat dan hukum-hukumnya.

\section{G. Pembayaran dan Distribusi Zakat Fitrah.}

1. Hukum zakat fitrah.

Perbedaan pendapat, Menurut jumhur adalah wajib, sedangkan sebagian Ulama mutaakhirin dari Ashab Maliki berpendapat zakat fitrah berhukum sunah, begitu pula penduduk irak. Satu kaum berpendapat zakat fitrah di naskh dengan zakat (Muhammad, 2010:257). 
2. Pembayaran zakat fitrah.

Ada yang berpendapat wajibnya zakat fitrah memilih membayar dengan gandum, kurma basah, anggur, atau dengan keju.pendapat yang lain, yang wajib dikeluarkan adalah makanan pokok yang umum disuatu daerah atau makanan pokok yang ditekankan, Bila tidak mampu mengeluarkan makanan pokok daerahnya, ini menurut pandapat yang diceritakan oleh abdul Wahab dari madzhabnya.

Ulama sepakat pengeluaran zakat fitrah darikurma basah tidak boleh kurang dari satu sha'ditetapkan dalam hadist ibnu 'umar. Ulama' berbeda pendapat dalam ukuran zakat fitrah dari jenis al-qomhu. Imam malik dan imam syafi'I berpendapat tidak cukup zakat fitrah dari jenis tersebut kurang dari satu sha', imam abu hanifah dan murid-muridnya berpendapat, cukup zakat fitrah dari jenis gandum merah $1 / 2 s h a$ '. (Muhammad, 2010:260).

3. Waktu pembayaran.

Ulama' sepakat waktu pembayaran zakat fitrah adalah di akhir bulan ramadhan, hadits ibnu'umar:

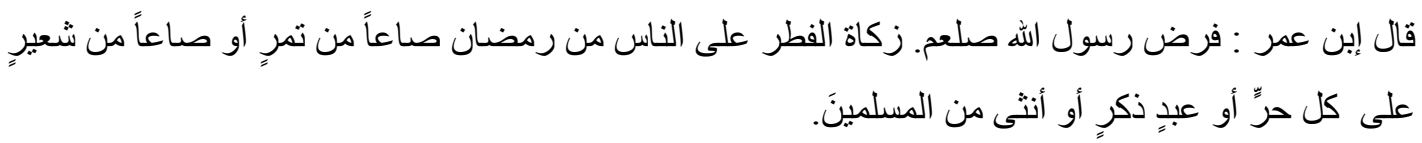

ulama' berbeda pendapat dalam hal pembatasan waktu (tahdid al wakti) imam malik berpendapat dalam riwayat ibnu qosim, wajib zakat fitrah dengan munculnya fajar hariied, diriwayatkan darinya asyhab, zakat fitrah wajib sebab terbenamnya matahari di akhir hari bulan ramadhan, imam ibnu hanifah sama dengan pendapat yang pertama, begitu pula imam syafi'i, sama dengan pendapat yang kedua.

4. Distribusi zakat fitrah.

Ulama' sepakat bahwa zakat fitrah wajib di tasharrufkan untuk orang-orang fakir yang muslim, sesuai dengan haditsNabi:

$$
\text { أَغنُو هم عنِ السُؤَال فحى هذا اليوم. }
$$

Ulama' berbeda pendapat, zakat fitrah menurut jumhur tidak boleh diberikan pada ahli Dzimmah, pendapat imam abu hanifah memper bolehkan nya. (Muhammad, 2010:261)

\section{H. Qodho' puasa, pembayaran kafarat dan fidyah.}

1. Qodho' puasa. 
Adapun hukum qodho' puasa bagi orang yang berpergian apabila berbuka (membatalkan puasa) maka para ulama' sepakat bahwa diwajibkanbagi orang yang meninggalkan puasauntuk mengqodho' puasa yang ditinggalkan, begitu juga dengan orang yang sakit sebagaimana firman allah:

$$
\text { فعدّةٌ من اياٍٍّ اخر. ( البقرة 185) }
$$

Artinya: maka diwajibkan mengganti puasa yang ditinggalkan pada hari yang lain.

Kecuali orang yang sakit epilepsy dan orang gila, dalam hal ini ulama' berbeda pendapat tentang kewajiban mengqodho' puasa bagi orang yang sakit epilepsy dan gila. (Muhammad, 2010:274)

2. Pembayaran kafarat dan fidyah.

Menurut imam syafi'idan imam ahmad pembayaran kafarat dan fidyah hanya diwajibkan bagi orang yang membatalkan puasa disebabkan karna jima'.

Berdasarkan hadits dari abuhurairoh:

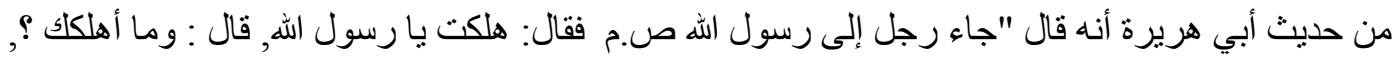

I. Syarat dan Rukun Haji.

Syarat-syarat wajib haji antara lain: Islam, baligh, berakal, merdeka dan mampu (istitha'ah). (Ahmad dan Al-Mughni, 164)

Rukun-rukun haji menurut empat madzhab adalah sebagai berikut: (Wahbah, 1985:497)

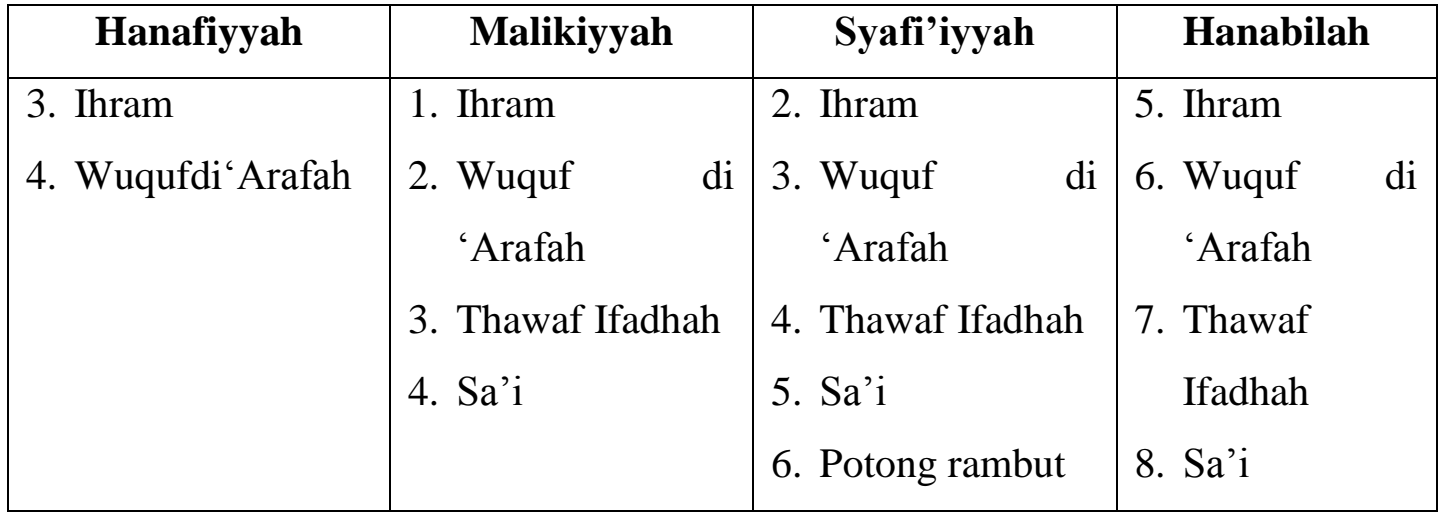

\section{J. Macam-macam Pelaksanaan Haji}

Pelaksanaan haji dan umroh dapat dilakukan dengan beberapa cara, yaitu:

a. Ifrod, yaitu melakukan ihram haji terlebih dahulu hingga selesai, kemudian melakukan ihram umroh secara terpisah. 
b. Tamattu', yaitu melakukan ihram umroh terlebih dahulu hingga selesai, kemudian melakukan ihram haji dalam musim haji itu juga.

c. Qiran, yaitu menggabungkan antara haji dan umroh. (Wahbah, 1985:507)

\section{K. Istitha'ah dalam Haji}

Istitha'ah dalam ibadah haji merupakan syarat wajib, yaitu suatu persyaratan dimana jika seseorang telah memenuhinya, maka ia diwajibkan melaksanakan ibadah haji. Dasar pijakan hukumnya ialah:

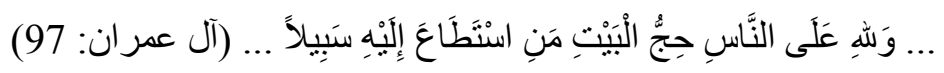

"Dan (di antara) kewajiban manusia terhadap Allah adalah melaksanakan ibadah haji ke Baitullah, yaitu bagi orang-orang yang mampu.” (Q.S. Ali 'Imron: 97) (Al-Qur'an dan Terjemahnya, 2005:32)

Pandangan empat madzhab tentang istiha'ah dalam haji:

a. Hanafiyyah

$$
\text { الإسنطاعة هى القدرة على الز ادو الر احلة، بشرط أن يكونا زائدين عن حاجيته الاصلية }
$$

"Istitha'ah adalah kesanggupan atas bekal dan kendaraan dengan syarat melebihi kebutuhan asalnya (kebutuhan pirmer).” (Rahman, 2011:573)

b. Malikiyyah

$$
\text { الإستطاعة هي إمكان الوصول إلى مكة ومو اضع النسك إمكانا ماديا }
$$

"Istitha'ah adalah memungkinkan sampai ke Makkah dan tempat-tempat ibadah haji secara materi." (Rahman, 2011:573)

c. Syafi'iyyah

Syafi'iyyah membedakan istitha'ah menjadi dua macam, yaitu istitha'ah bi alnafs dan istitha'ah bi al-ghair.Istitha'ah bi al-nafs harus memenuhi beberapa unsur berikut:

1. Mampu berbekal.

2. Memiliki kendaraan.

3. Keamaan dalam perjalanan.

4. Memiliki air, bekal dan pangan untuk tunggangannya. Dalam konteks sekarang, bisa dikatakan memiliki bahan bakar kendaraan.

5. Bersama suami atau mahramnya (untuk perempuan).

6. Sanggup bertahan dalam kendaraan tanpa menimbulkan bahaya. 
7. Memiliki waktu yang cukup untuk menyelesaikan ibadah haji. (Rahman, 2011:575)

d. Hanabilah

$$
\text { ومسكن وخادم ونفقة عياله على الدوام الزاد والراحلة الصالحة لمنله ويشترط أن يكونا فاضلين عما يحتاجه من كتب علم }
$$

"Istitha'ah adalahkesanggupan atas bekal dan kendaraan yang layak secara umum. Dan disyaratkan keduanya melebihi kebutuhan-kebutuhan semacam kitab-kitab ilmu, tempat tinggal, pelayan serta nafkah keluarganya." (Rahman, 2011:574)

\section{PENUTUP}

\section{A. Kesimpulan}

Berdasarkan hasil pembahasan artikel ini dapat disimpulkan sebagai berikut:

1. Niat ialah bermaksud melakukan sesuatu. Niat dalam beribadah difungsikan untuk membedakan antara satu ibadah dengan yang lain agar tidak terjadi kerancuan.

2. Bersuci atau thaharah didefinisikan sebagai bersih dari najis, baik berbentuk konkret yang berupa kotoran maupun abstrak yang berupa hadats.

3. Terkait bacaan basmalah dalam sholat, 'ulama empat madzhab berbeda pandangan. Hanafiyyah dan Hanabilah mengatakan bahwa membaca basmalah dalam sholat berhukum sunnah, Syafi'iyyah mengatakan berhukum wajib, sedangkan Malikiyyah mengatakan berhukum makruh.

4. Membaca do'a iftitah menurut Hanafiyyah, Syafi'iyyah dan Hanabilah berhukum sunnah. Sedangkan menurut pendapat masyhur Malikiyyah berhukum makruh.

5. Menurut empat madzhab Hanafiyyah, Malikiyyah, Syafi'iyyah dan Hanabilah, sholat jama'ah berhukum sunnah atau fardhu kifayah. Sedangkan menurut madzhab dzhahiriyyah, sholat berjama'ah berhukum fardhu 'ain.

6. Hukum salat jum'at, Shalat jum'at berhukum fardu bagi setiap orang muslim yang sudah balig dan berakal.

7. Hukum zakat fitrah terdapat perbedaan pendapat, menurut jumhur adalah wajib, sedangkan sebagian Ulama mutaakhirin dari Ashab Maliki berpendapat zakat fitrah berhukum sunah. 
8. Khodho puasa wajib bagi orang yang meningalkan baik karna bepergian atau karana sakit, khusus bagi oaring yang membatalkan puasa karena persetubhan di kenakan kafarat dan fidiyyah.

9. Syarat-syarat wajib haji antara lain: Islam, baligh, berakal, merdeka dan mampu (istitha'ah).

10. Pelaksanaan haji dan umroh dapat dilakukan dengan beberapa cara, yaitu:
a. Ifrod
b. Tamattu
c. Qiran

11. Istitha'ah dalam ibadah haji merupakan syarat wajib, yaitu suatu persyaratan dimana jika seseorang telah memenuhinya, maka ia diwajibkan melaksanakan ibadah haji.

\section{DAFTAR RUJUKAN}

Al-Qur'an dan Terjemahnya. 2005. Yayasan Penyelenggara Penterjemah/ Pentafsir alQur'an, Bandung: Penerbit Jumanatul 'Ali Art.

Al-Zuhailiy, Wahbah. 1985. Al-Fiqh al-Islamiy wa Adillatuh. Damaskus: Dar al-Fikr. (Maktabah Syamilah)

Ibn Rusyd, Muhammad. 1995. Bidayah al-Mujtahid wa Nihayah al-Muqtashid. Kairo: Dar al-Salam.

Al-Jaziriy, Abdur Rahman. 2011. Al-Fiqh 'Ala al-Madzhahib al-Arba'ah. Beirut: Dar al-Kutub al-'Ilmiyyah.

Ibn Qudamah, Abdullah bin Ahmad. Al-Mughni, Beirut: Dar al-Fikr, tt. (Maktabah Syamilah) 